\title{
A Varig e o Brasil entre o desenvolvimento nacional e a competitividade global
}

\author{
Cristiano Fonseca Monteiro*
}

\section{Introdução}

A literatura a respeito do mundo empresarial, tanto acadêmica quanto jornalística, tem se demonstrado cada vez mais interessada por questões de natureza "social". Ao contrário do que parecia sugerir em seus momentos iniciais, o processo de globalização econômica, assim como as exigências de maior competitividade, acabaram por abrir espaço para novas leituras sobre o comportamento das empresas, dos empresários e da relação de ambos com a sociedade. A crescente importância atribuída a valores "intangíveis" como o conhecimento, a liderança, as redes e a cultura da empresa mostra que uma abordagem meramente econômica - ou ainda, economicista - não é capaz de dar conta da complexidade do universo empresarial, e que, portanto, novos olhares precisam entrar em cena. ${ }^{1}$

* Doutor em Sociologia pela Ufrj; Professor Adjunto de Sociologia (Depto. de Administração) UFF/ Pólo Universitário de Volta Redonda. fonsecamonteiro@yahoo.com.br; cmonteiro@metal.eeimvr.uff.br

1 Para uma apreciação do esforço recente em organizar uma abordagem sociológica sobre as empresas, ver as coletâneas organizadas por Kirschner e Gomes (1999) e Kirschner et al. (2002).

\begin{tabular}{|l|l|l|l|l|l|}
\hline Civitas & Porto Alegre & v. 7 & n. 1 & jan.-jun. 2007 & p. 35-58 \\
\hline
\end{tabular}


De um ponto de vista teórico, alternativas às interpretações que têm reduzido o mundo econômico em geral, e as empresas em particular, a uma racionalidade formal de cunho economicista têm surgido a partir da literatura da nova sociologia econômica. Esta literatura busca resgatar importantes traços da teoria sociológica clássica (Marx, Weber, Durhkeim, Schumpeter) ligados à análise das instituições econômicas - a fábrica e seus atores, a burguesia e seu ethos, os mecanismos de regulação social e o próprio capitalismo como regime de produção ${ }^{2}$ - para se contrapor às interpretações reducionistas já aludidas.

Neste artigo, procuro desenvolver uma interpretação de um importante agente econômico - a empresa - em sua relação com o meio social, tomando como referência duas vertentes distintas, porém complementares, da análise sociológica sobre o universo econômico. Primeiramente, utilizo-me da noção desenvolvida pela nova sociologia econômica de que a ação econômica é uma forma de ação social. ${ }^{3}$ Em segundo lugar, lanço mão das contribuições da Sociologia da Empresa francesa, cujos autores têm procurado desenvolver, por um lado, a noção de que a empresa não é apenas um espaço de reprodução de relações sociais de natureza estrutural (luta de classes; dominação racional-legal), mas também um espaço que cria diferentes formas de sociabilidade (Sainsaulieu, 1997; Bernoux, 1995). Por outro, e esta é a perspectiva que mais interessa neste artigo, entendem a empresa como um ator social, ator este que constrói laços com o meio em que está inserido (Liu, 1992; Sainsaulieu, 1992). ${ }^{4}$

Através de suas dinâmicas internas (Francofort et al., 1995) e de suas estratégias (Ramanatsoa, 1992), as empresas se revelam atores que interagem com a sociedade (re)produzindo valores, símbolos, cultura e poder, isto é, produzindo relações que estão impregnadas de significado, cuja compreensão

2 A bibliografia sobre o tema é vasta em língua estrangeira, e começou recentemente a ser traduzida e debatida no Brasil. Para uma visão introdutória, ver Wanderley (2002) e Lopes Jr. (2002).

3 Esta abordagem sugere que a "inserção social da economia" formulada por Polanyi (1944) não se extingue com o surgimento das economias modernas. Uma das tarefas da pesquisa sociológica contemporânea seria, neste sentido, explorar a dimensão social das relações econômicas. Ver, a respeito, Swedberg e Grannoveter (1992).

4 No Brasil, Kirschner e Monteiro (2002) procuram estabelecer uma ponte entre a Nova Sociologia Econômica e alguns dos principais trabalhos da Sociologia da Empresa francesa. 
seria uma das tarefa de uma sociologia da empresa. Desta forma, a ruptura com as análises de cunho economicista passa, entre outros caminhos, por explorar a noção de empresa como ator social, tomando como foco de análise as suas estratégias. Geralmente tratadas apenas como respostas "eficientes" para o problema da sobrevivência no mercado e a busca da lucratividade, pretende-se mostrar que estas estratégias articulam concepções substantivas em termos políticos, econômicos, culturais - sobre a atividade econômica. ${ }^{5}$

Sob tal prisma, este artigo analisa a trajetória da Varig ao longo de dois momentos do desenvolvimento da aviação comercial no Brasil (anos 1960-70 e anos 1990), com especial atenção às estratégias com as quais a empresa procurou se articular à dinâmica do desenvolvimento da economia brasileira nestes contextos. Procuro mostrar que a Varig construiu sua trajetória, de pequena empresa a líder no mercado, através de estratégias que envolveram a constante articulação com o poder público. Ela foi bem sucedida num momento em que o Estado capitaneou o processo de desenvolvimento econômico do país, intensificando seu controle sobre o transporte aéreo, entre as décadas de 1950 e 1970. Neste período, a Varig procurou construir uma imagem de "empresa a serviço do país", articulando-se especialmente ao modelo de desenvolvimento de "Brasil Grande" dos governos militares. ${ }^{6}$

Na década de 1990, a Varig se vê desafiada por um novo modelo econômico baseado no retraimento do Estado e na ênfase no livre-mercado. A entrada de novos atores no mercado de aviação comercial e um novo padrão de interação do poder público com as empresas coloca desafios que a Varig procura enfrentar, substituindo gradativamente a estratégia anterior por uma estratégia de "competitividade global". A imagem da "Varig Grande" cede, então, espaço para uma imagem de empresa "enxuta", voltada para os resultados financeiros. Este trabalho não pretende discutir a crise que marcou os primeiros anos do século XXI e que levou a empresa à quase paralisação de suas atividades. Mas a compreensão das contradições e ambigüidades que marcaram os anos 1990 pode ajudar a lançar luz sobre os impasses que se

Sobre a noção de "construção social da eficiência", ver ainda Fligstein (1990).

6 Antes de mim, Xausa (1993) também procurou mostrar as diferentes formas como a Varig constituiu simbolicamente sua relação com clientes, funcionários e o conjunto do país. O trabalho, no entanto, é feito de um ponto de vista distinto do aqui proposto, estando mais preso ao discurso da própria Varig, sem referenciá-lo à dinâmica política e econômica do país. 
sucederam, assim como abre portas para questionamentos sobre alguns dos pressupostos que orientaram a visão economicista que prevaleceu sobre o mundo empresarial naquele período. Estes aspectos serão abordados na conclusão.

\section{O surgimento e consolidação da Varig: entre o empreendedorismo e os laços com o poder público ${ }^{7}$}

Desde a I Guerra Mundial, a atividade aeronáutica havia se revelado um poderoso instrumento militar, alcançando significado estratégico para os países que vislumbravam algum grau de liderança internacional. No entreguerras, a aviação podia ser considerada um campo aberto de luta entre nações que detinham tecnologia - como a Alemanha, Estados Unidos e França - e visavam por meio dela expandir sua hegemonia pelo mundo. Ao mesmo tempo em que procuravam desenvolver novos aviões, estes países procuraram estimular a criação de linhas aéreas em outros continentes, inclusive na América do Sul. O surgimento da Varig está ligado a este jogo de poder, que levou o governo alemão a prover a tecnologia e a mão-de-obra especializada a um projeto capitaneado por um emigrante daquele país, que tentava fundar no sul do Brasil uma empresa de transporte aéreo.

O alemão Otto Ernst Meyer vinha mobilizando apoio político e econômico na cidade de Porto Alegre desde 1925, tendo conseguido que o presidente da Província do Rio Grande do Sul, Borges de Medeiros, levasse à Assembléia Legislativa uma proposta de concessão de isenção fiscal ao empreendimento. O apoio veio com a aprovação da lei 413, a qual isentava de taxas e impostos, num prazo de 15 anos, empresas que se fundassem para explorar a navegação aérea. Neste como em outros passos dados pela empresa em gestação, a capacidade de articulação com o poder público seria a mola propulsora de seu desenvolvimento, e a importância estratégica da atividade do ponto de vista militar, político e econômico - seria recorrentemente lembrada para justificar esta articulação.

7 Para esta fase, foram consultados Anderson (1979), Davies (1984), Pereira (1987) e Ribeiro (2002). 
Com o apoio político (e financeiro, pode-se dizer) garantido no Rio Grande do Sul, Meyer conseguiu negociar com o grupo alemão Condor Syndikat a participação de $21 \%$ das ações da nova empresa, que foram representados pelo hidroavião Dornier Wal utilizado na linha a ser explorada, ligando Porto Alegre às cidades de Rio Grande e Pelotas (a "Rota da Lagoa"). Além do incentivo do governo gaúcho e da participação do grupo alemão, Otto Meyer conseguiu angariar apoio de proprietários e comerciantes, muitos de origem germânica como ele, que participaram da constituição do capital que deu origem à primeira empresa de aviação comercial brasileira (Fundação Ruben Berta 1996, p. 54). ${ }^{8}$ A Varig SA - Empresa de Viação Aérea RioGrandense - foi oficialmente registrada como empresa privada em 7 de maio de 1927, tendo recebido em 10 de junho seguinte, pelo Decreto 17.832, autorização para voar para todo o Rio Grande do Sul, litoral de Santa Catarina, e para Montevidéu, esta última rota dependendo de autorização por parte do governo uruguaio.

A falta de um aparato institucional, os poucos recursos tecnológicos disponíveis e a virtual inexistência de uma infra-estrutura de apoio ao vôo levaram os historiadores da aviação a falar dos primeiros anos da atividade no Brasil como uma fase "heróica". A comunicação aeronáutica era precária ou inexistente e a navegação se baseava principalmente na intuição dos pilotos, que deviam fazer também as vezes de mecânicos (quando, por exemplo, o avião era obrigado a pousar fora de uma base, o que não era raro). Não havia aeroportos, mas apenas "campos de pouso", alguns deles dotados de pequenas casas à guisa de terminais, tudo construído pelas próprias empresas.

A Varig representa bem esta fase inicial da aviação comercial no Brasil por ter se lançado à verdadeira aventura que representava voar naquele

8 Num estudo de caráter exploratório sobre alguns fatores intervenientes na criação da empresa, Nadja Brandão traça um panorama sócio-político-econômico da Porto Alegre dos anos 20, e mostra a origem dos primeiros acionistas da Varig, na sua maioria, alemães, havendo também alguns brasileiros sem raízes familiares germânicas, mas que estudaram naquele país. O estudo procura mostrar que houve uma convergência de fatores, dentre os quais se destacam a mentalidade positivista do então presidente da Província, Borges de Medeiros (e portanto, afeita à idéia de progresso, de que o avião seria um expoente), e notadamente a solidariedade de uma comunidade empresarial - pequenos proprietários, fazendeiros e comerciantes - teuto-brasileira para com Otto Meyer (Brandão, 1994). 
período e ter inaugurado rotas para todo o interior do Rio Grande do Sul nas condições descritas acima. Até o ano de 1930, ela o fez contando com o suporte técnico do Condor Syndikat e, portanto, como parte da estratégia alemã de expandir sua hegemonia. Naquele ano, no entanto, o grupo alemão decidiu atuar no mercado nacional com uma empresa própria, que se chamaria Sindicato Condor. Da mesma forma, os norte-americanos já haviam fundado a Panair do Brasil, subsidiária da Pan American Airlines. Por conta da mudança de estratégia, o grupo alemão retirou sua participação na Varig, então representada por dois aviões em operação. Com isso, a Varig chegou a ficar alguns meses sem voar, e a solução encontrada foi recorrer ao governo gaúcho, que se tornou acionista da empresa. ${ }^{9}$ Com estes recursos, a Varig pôde receber novos aviões e continuar expandido suas rotas, que se estenderam até Santa Catarina e, já em 1941, a Montevidéo.

O significado político da aviação comercial se fez mostrar mais uma vez durante a Segunda Guerra Mundial, trazendo implicações para as empresas em operação no Brasil. A posição do governo brasileiro a favor dos aliados fez prevalecer um sentimento anti-germânico, e as empresas brasileiras que tinham ligações com aquele país tiveram que se adaptar aos novos tempos. Os aviões de fabricação alemã foram substituídos por outros de fabricação francesa, inglesa e principalmente norte-americana. O Sindicato Condor foi nacionalizado, tendo seu nome mudado para Cruzeiro do Sul, e seus diretores alemães foram substituídos por brasileiros. Da mesma forma, na Varig, Otto Meyer se retirou da presidência dando lugar a Ruben Martin Berta.

Foi neste período que se deu a criação da Fundação dos Funcionários da Varig, que posteriormente seria rebatizada como Fundação Ruben Berta. A criação desta fundação costuma ser tratada pela propaganda institucional da empresa como mais um ato de empreendedorismo e de compromisso social de seus líderes. ${ }^{10}$ Ao idealizar a fundação, Berta lançou mão de um discurso orientado pela doutrina social da igreja católica e recebeu o apoio de líderes

9 Solução semelhante à encontrada pela Vasp para escapar da virtual falência poucos anos após sua criação. Fundada por um grupo de empresários paulistas em fins de 1933, já em 1935 teve suas atividades paralisadas. Através da entrada de capital do Estado de São Paulo, que se tornou seu acionista majoritário, a empresa recebeu um aporte que lhe permitiu retomar suas atividades.

10 Ver, por exemplo, Fundação Ruben Berta (1996). Esta visão, no entanto, também é endossada por trabalhos acadêmicos, como os de Gonçalves (1987) e Xausa (1993). 
trabalhistas para um projeto de "capitalismo social" no qual os trabalhadores se tornariam proprietários da empresa. Assim, ele foi capaz de convencer os acionistas privados e o governo do Rio Grande do Sul a passar suas ações à fundação, que se tornou a acionista majoritária. ${ }^{11}$

Quanto ao aspecto institucional, a Segunda Guerra Mundial também deu as bases para transformações de vulto no cenário da aviação mundial. Após o conflito, foram criados organismos e um conjunto de normas visando regulamentar a atividade em nível internacional. ${ }^{12}$ No Brasil, especificamente, foram construídos aeroportos e uma considerável infraestrutura de apoio ao vôo, além de se ter disponibilizado recursos humanos tecnicamente qualificados. Por fim, centenas de aviões utilizados durante o conflito (C-47 e DC-3) foram vendidos a preços irrisórios, permitindo o surgimento de duas dezenas de empresas e a multiplicação de cidades servidas no país. ${ }^{13}$

A Varig aproveitou as oportunidades surgidas com esta onda e iniciou sua expansão para o norte e nordeste brasileiro. Em 1952, comprou a empresa Aeogeral, extendendo seus vôos até Natal. Neste período, saltou da condição de pequena empresa regional para uma empresa de porte nacional. Logo em seguida, conseguiu negociar junto ao governo federal a concessão para uma importante rota internacional, que até então não era operada por empresas brasileiras. O vôo para Nova Iorque, inaugurado em 1955, permitiu à Varig ascender ao grupo das grandes empresas nacionais.

11 Dentro desta filosofia, a direção da empresa deveria ser submetida ao controle de um colégio deliberante, formado pelos próprios funcionários. Mas como foi relatado por pessoas que trabalharam na empresa sob a direção de Ruben Berta, ele próprio indicava os representantes do conselho, que pouco espaço tinha para discutir as decisões tomadas pelos dirigentes. Assim, em depoimentos de ex-funcionários o referido conselho foi descrito como "extremamente subserviente", sendo conhecido pelos mais críticos como "conselho concordante". As entrevistas foram concedidas ao autor ao longo de 1999 por funcionários aposentados da Varig.

12 A Convenção de Chicago (1944), a criação da International Civil Aviation Organization e da International Air Transport Association foram os principais marcos. A respeito, ver Monteiro (2000).

13 Segundo Dole Anderson, em 1940 havia quatro empresas operando em 85 cidades. Em 1950, havia 19 empresas atuando em 204 cidades. Embora o número de empresas tenha diminuído a partir de então, ao longo dos anos 1950 chegou-se a voar para 344 localidades (Anderson, 1979, p. 80). 
O episódio da concessão desta rota seria novamente emblemático da centralidade da estratégia de aproximação com o governo, e o quanto o investimento neste jogo político seria decisivo para que a empresa gaúcha viesse a ocupar um lugar de destaque no cenário da aviação comercial. O depoimento do ministro da Aeronáutica no segundo governo de Getúlio Vargas, Brigadeiro Nero Moura, mostra que o então presidente da Varig, Ruben Berta, se beneficiou da condição de colaborador da campanha de Vargas para conseguir a rota para Nova York, como segue:

em um dos primeiros despachos que tive com Getúlio, o presidente disse: "O Berta ajudou muito na campanha, e eu gostaria que você olhasse com simpatia as pretensões da Varig, atendendo-as com boa vontade". O Berta veio no dia seguinte apresentar suas "pretensões". Propôs-se a assumir a rota da Cruzeiro (para Nova Iorque) sem subvenção (Moura, 1996, p. 255). ${ }^{14}$

A inauguração da rota para Nova Iorque seria o início de uma trajetória em que a Varig se constituiria como a principal empresa do mercado de aviação comercial brasileira. Sua estratégia envolveria a aproximação com o poder público - quaisquer que fossem os grupos nele dominantes - de forma a garantir o acesso ao mercado. Este padrão se confirmaria nas décadas seguintes, sendo fator decisivo para o sucesso da empresa nas décadas 1960 e 1970 e, da mesma forma, ajudando a entender as dificuldades enfrentadas a partir dos anos 1990.

\section{Os anos 1960-1970: a Varig e o Brasil "grandes"}

$\mathrm{Na}$ virada para a década de 1960, o cenário da aviação comercial era de crise. Era evidente a redução no tráfego aéreo nacional, tanto em função das seguidas falências e/ou incorporações de companhias, quanto em função da redução no número de cidades atendidas pelos serviços aéreos, por conta da entrada em operação de aeronaves de maior porte, incompatíveis com os pequenos e precários campos de pouso que haviam proliferado em todo o território nacional até então. Já em 1959 havia sido criada uma Comissão Parlamentar de Inquérito na Câmara dos Deputados para investigar o que se reconhecia como uma séria crise do setor. Entre 1961 e 1968 foram realiza-

14 Ao contrário do que afirma o Brigadeiro, no entanto, a Varig contou com o apoio financeiro do governo federal, como todas as empresas da época que operavam rotas internacionais. 
das três Conferências Nacionais de Aviação Civil (as Conacs), nas quais autoridades governamentais e empresários se reuniram para tentar esclarecer as causas da crise e buscar soluções. ${ }^{15}$

Estas conferências colocaram em discussão temas como o perfil da demanda a ser atendida e o papel do poder público e da iniciativa privada. Quanto ao perfil da demanda, até 1964, colocou-se em pauta a criação de classes diferenciadas de serviços, procurando atender diferentes tipos de passageiros. Um dos consensos entre os principais envolvidos era a prioridade à iniciativa privada na exploração dos serviços, embora se reconhecesse a necessidade de um maior controle do poder público - a excessiva liberalidade como a aviação vinha sendo tratada até então era percebida como uma das causas para a crise. A criação de uma estatal do setor, discutida pelos trabalhadores e pela comunidade acadêmica, foi amplamente repudiada. Deve-se mencionar também o tema da concessão de subsídios e a necessidade de se retomar os vôos para as localidades interioranas.

O golpe de 1964 forçou a definição de algumas destas questões, com a afirmação de dois princípios que passariam a nortear a atividade a partir de então: a "competição controlada" e a "realidade tarifária". Pelo primeiro, estipulou-se um rigoroso controle da oferta de assentos, procurando-se evitar que as empresas oferecessem vôos em horários coincidentes, a menos que houvesse demanda comprovada. As tarifas eram padronizadas, a partir de uma base de custos informada pelas empresas ao órgão controlador, o Departamento de Aviação Civil. Quanto ao segundo princípio, entendia-se que as empresas não deveriam depender de subsídios governamentais, de modo que os usuários deveriam arcar com os custos da operação, o que implicava a concentração do serviço nas classes de maior poder aquisitivo. As rotas de integração nacional continuariam recebendo subvenções, sendo que um modelo definitivo só se concretizaria em meados dos anos 1970.

A definição do modelo de designação para as rotas internacionais mais uma vez revelou a capacidade da Varig de se articular ao núcleo de poder, independente de seus ocupantes. Apesar da estreita ligação com Getúlio Vargas, que se estenderia a seus herdeiros políticos (João Goulart e Leonel Brizola), Berta foi capaz de aproximar-se dos governos militares e, graças a esta

15 Para uma análise pormenorizada das diferentes dimensões desta crise, ver Fay (2001). 
aproximação, garantir que a empresa gaúcha viesse a alcançar, com exclusividade, a condição de "empresa de bandeira" do Brasil. O evento que levou a este desfecho foi a decretação da falência da Panair do Brasil, em 1965. ${ }^{16}$

Cercada de polêmicas, a medida tomada por Castello Branco foi justificada pelas autoridades aeronáuticas pela situação financeira e operacional crítica em que se encontraria a empresa. No entanto, um livro de memórias da Panair argumenta que a linha aérea teria sido vítima da ação discricionária dos militares. Entre outros pontos, sustenta-se que a falência foi decretada apesar da empresa estar com os salários de seus funcionários em dia e não ter títulos vencidos (cf. Barbosa, 1996). ${ }^{17}$

Graças à habilidade política de seus dirigentes, a empresa gaúcha passou a ocupar uma posição confortável no mercado de aviação comercial brasileiro. Os Relatórios da Administração da Varig demonstram que o período entre 1964 e fins dos anos 70 foi aquele de maior prosperidade para a transportadora. Ela alcançou uma posição de liderança expressiva nos mercados internacionais (América do Norte, Europa, Ásia e, posteriormente, África), e obteve seguidos resultados positivos no seu balanço, além de ter crescido em todos os sentidos: frota, rotas, funcionários, faturamento, entre outros. A liderança no segmento internacional veio a se reproduzir no cenário doméstico, alcançando fatias crescentes do mercado. Com a incorporação da Cruzeiro do Sul,

16 Na verdade, a Varig dividiu parte das rotas internacionais com a Cruzeiro do Sul. Mas a esta, couberam apenas os vôos para a América do Sul, enquanto a empresa gaúcha ficou com as rotas consideradas "nobres", de longa distância. Em meados da década de 1970, no entanto, a Cruzeiro do Sul faliu e acabou sendo incorporada pela Varig, que passou a deter $100 \%$ das rotas internacionais.

17 O livro traz também um relato sobre o processo de nacionalização da Panair, com a venda de seu controle para um grupo liderado por Celso da Rocha Miranda, durante o governo Jânio Quadros, a quem Rocha Miranda era ligado politicamente. Naquele momento, houve uma desconfiança por parte das autoridades de que o objetivo da aquisição seria uma posterior venda da Panair à Varig, uma vez que um dos membros do grupo comprador, Erik de Carvalho, era também dirigente da empresa gaúcha. Um diretor do DAC chegou a chamar Rocha Miranda e o presidente da Panair, Paulo Sampaio, para uma reunião, onde fez uma ameaça: "Gostaria de saber se esta aquisição tem como finalidade transferi-la para a Varig. Se tem, quero avisar que não permitirei que se constitua um monopólio que só virá a prejudicar os interesses nacionais. Antes que se constitua a Bertabrás, eu constituirei a Aerobrás" (Barbosa, 1996, p. 69). Curiosamente, após o golpe, os próprios militares se encarregariam de criar, com a polêmica decretação da falência da Panair, o que muitos críticos chamariam de "Bertabrás" - uma empresa privada, detentora do monopólio da designação para os vôos internacionais. 
em meados da década de 1970, sua participação chegou a 50\%, posição que se manteria até o início dos anos 1990.

Para além dos números, no entanto, a construção de uma imagem de "empresa do país" precisava ser sempre atualizada simbolicamente, e foi neste sentido que Erik de Carvalho, sucessor de Ruben Berta (morto em 1966), pautou a sua estratégia. Além de transportar os Presidentes da República em seus deslocamentos internacionais, a Varig também se tornou a transportadora da seleção brasileira de futebol. Por ocasião da viagem de retorno da equipe tri-campeã do mundo em 1970, o então presidente da Varig (que acompanhava a delegação) demonstrou senso de oportunidade num anúncio feito a bordo, como segue:

A conquista definitiva da Taça Jules Rimet representa, sem dúvida, o maior feito do futebol mundial em todos os tempos. Por isso mesmo, os 90 milhões de brasileiros constituíram-se, sob a invulgar e patriótica liderança do Exmo. Sr. Presidente Emílio G. Médici, na maior e mais vibrante torcida que já se uniu, em qualquer época (Rosa dos Ventos, n. 37, 1970, s.p.).

O transporte das comitivas e de lideranças políticas criou outras oportunidades de afirmar a identidade de "empresa oficial", como por exemplo, na introdução de um novo avião em sua frota, ou quando da inauguração de um novo vôo. Foi o caso do lançamento do Boeing 727-100 e da implementação de um vôo entre Porto Alegre e Brasília, que em sua inauguração transportou autoridades de toda a região sul, tendo sido a comitiva recebida por Médici, ambos acontecimentos ocorridos em 1970 (Rosa dos Ventos, n. 39, 1970, p. 5; n. 43, 1970, p. 3-4)

Sintetizando a estratégia de articulação com o poder político, o Relatório Anual de 1971 da diretoria da Varig reconhece a importância da colaboração dos funcionários, da confiança dos acionistas, da fidelidade dos passageiros e afirma:

em toda a sua profundidade, é esse reconhecimento extensivo ao nosso Governo que, desde a salvadora Revolução de março de 1964, achava-se voltado para a inadiável obra de criar, no Brasil, as condições básicas e autênticas para o desenvolvimento sócio-econômico, em ritmo acelerado e auto-sustentável, como síntese perfeita da 'grande tarefa nacional' que hoje a todos os brasileiros cabe executar. E em meio a este panorama de uma Nação que procura desenvolver-se à altura da grandeza de seu território, de sua tradição e de seu povo, não poderia a Va- 
rig faltar com seu esforço e colaboração em sua importante área de atividade: o transporte aéreo (Relatório Anual da Diretoria, 1971, p. 5).

Neste contexto, a Varig se identifica como parte de um esforço no sentido da integração, modernização e desenvolvimento nacional em harmonia com os projetos governamentais, pautando-se numa representação de "Brasil Grande", e por extensão, "Varig Grande". Em meio a tais referências é que a Varig se lança às mais variadas estratégias de diversificação, entre elas a organização de uma rede de hotéis, prática disseminada entre as empresas de aviação no período. Além disso, com a criação do Sistema de Transporte Aéreo Regional, a Varig funda, em parceria com empresas ligadas à atividade de seguros a Rio-Sul Linhas Aéreas (Relatório Anual da Diretoria, 1976, p. 33)

Numa propaganda, reproduzida no interior do Relatório Anual de 1968, aparece um avião da empresa junto a um radar, simbolizando o sentido modernizador para que apontava o país. A foto é acompanhada do seguinte texto:

Com mais aviões, mais vôos e em contínua expansão, a Varig também está em ritmo de Brasil grande. [...] Transportando mais passageiros, movimentando mais carga, e muito especialmente levando a todos os quadrantes nacionais e internacionais o irreversível progresso da nação brasileira (Relatório Anual da Diretoria, 1968, s.p.).

Num outro relatório, aparece também uma interpretação sobre a importância da ação da Varig para o desenvolvimento do país, salientando a permanência de recursos no Brasil assim como a divulgação de uma imagem positiva do país no exterior.

Atuando como importante fator para o fortalecimento da economia nacional, pari passu com a crescente projeção do Brasil no cenário mundial, a Varig apresentou em 1970 uma receita internacional correspondente a 97 milhões de dólares, os quais, se ausente estivesse a bandeira brasileira, teriam sido carreados por empresas de outros países (Relatório Anual, 1970, p. 20).

As estratégias da Varig também podem ser lidas sociologicamente através da sua concepção do serviço prestado. Além da relação com uma determinada ideologia do desenvolvimento, a Varig constituiu "estratégias de mercado" na competição - que de fato existia, especialmente no segmento internacional - com as demais empresas. Nesta estratégia, prevalece um foco 
no serviço sofisticado, atendendo os segmentos de elite da população para os quais as autoridades aeronáuticas haviam se voltado conforme os princípios da "competição controlada" e da "realidade tarifária".

A Varig, pelo menos desde a inauguração dos vôos para Nova Iorque em 1955, pautou sua estratégia de competitividade no oferecimento de um serviço de bordo de luxo. Segundo relato de funcionários, o vôo para Nova York, quando era operado por um Boeing 707, já nos anos 1970, tinha metade de sua cabine dedicada à primeira classe, dando idéia do perfil do usuário visado pela empresa (e portanto, do uso social que se queria emprestar ao serviço de transporte aéreo). Numa propaganda deste vôo, tem-se idéia do significado que se buscava construir para o serviço oferecido pela empresa: "Oferecemos todos os dias um banquete de 120 talheres. Reserve o seu lugar na mesa RioNew York" (Rosa dos Ventos, n. 45, 1971, s.p).

O princípio da "realidade tarifária" seria mencionado em um relatório anual, que afirma:

fator fundamental ao êxito do empreendimento continua sendo a política de verdade tarifária, única capaz de assegurar as correções imediatas impostas pelo agravamento de custo oriundo de fatores exógenos, característicos de uma economia ainda em processo inflacionário, embora auspiciosamente regressivo (Relatório Anual da Diretoria, 1970, p. 6).

Este padrão de regulação vigorou ao longo dos anos 1970, e foi fundamental para o desempenho da Varig. Mas as condições políticas e econômicas que deram lastro a este modelo logo se veriam questionadas. A virada para a década de 1980 seria marcada pelo fracasso do projeto de "Brasil grande", e pela entrada em cena de novos temas na agenda política e econômica. A Varig, por sua vez, apresentaria um certo descompasso em relação à agenda governamental, mantendo-se fiel às estratégias da "Varig grande" até meados da década de 1990, quando passa a se orientar por uma estratégia mais consistente com a agenda da globalização e da "competitividade global”. Este período será discutido na próxima seção. 


\section{Anos 1990: a Varig e o Brasil em busca da "competividade global"}

Diante da crise do modelo de desenvolvimento baseado na intensa participação e controle do Estado na esfera econômica, ganhou espaço uma política de orientação liberalizante, baseada no retraimento do Estado e na aposta no livre mercado como mecanismo privilegiado de coordenação entre os atores econômicos. Estas mudanças, as "reformas para o mercado", se deram no interior de um processo mais amplo de globalização, tendo como mote a abertura dos mercados nacionais à concorrência internacional. Globalização e "reformas para o mercado" seriam movimentos complementares que, sob muitas leituras, representariam o "fim da história", ou ainda, o "fim da política", uma vez que as escolhas estariam limitadas num contexto em que a única alternativa seria a inserção na competição no mercado globalizado. ${ }^{18}$

Um dos principais argumentos contra a perspectiva da convergência das diferentes trajetórias (locais, nacionais, regionais) para um padrão global de estruturação da ordem econômica é de que os legados históricos e as disputas políticas determinam o próprio processo de inserção no contexto de globalização. Esta percepção se confirma quando observamos que as estratégias da Varig não acompanharam de forma mecânica as mudanças na política econômica governamental no sentido da abertura. Num ambiente totalmente distinto daquele em que se projetou como um dos grandes símbolos do "Brasil Grande", a Varig levou alguns anos para abandonar as estratégias de "Varig Grande".

Com a eleição de Collor, introduziu-se no Brasil uma série de mudanças na aviação comercial que começaram com o fim da exclusividade da Varig na designação para vôos internacionais e com a privatização da Vasp. Do ponto de vista da política macroeconômica, iniciou-se o tempo das medidas de controle da inflação via redução na demanda, que levariam a década de 1990 a ser uma segunda década perdida em termos de crescimento econômico. Quanto a estas medidas, uma peça publicitária veiculada pela Varig em

18 Os discursos que procuraram associar a globalização à idéia de "fim da história" ganharam alguma notoriedade entre as décadas de 1980 e 1990, mas logo foram superados por inúmeros trabalhos que, a partir de dados empíricos e reflexões teóricas, evidenciaram a sua inconsistência. Autores como Drache (1996), Ianni (1996) e Diniz (2000), entre outros, discutem estas abordagens, argumentando que a globalização não anula, mas complexifica o jogo político entre as dinâmicas locais, nacionais e regionais e aquelas de natureza global. 
1991 mostra a visão da empresa sobre o novo ambiente: "Aeroportos e vôos vazios. Para acabar com a inflação, empurrar o país para a modernidade, criar uma saudável economia de mercado, temos mesmo que passar por algumas dificuldades."

Inicialmente, a empresa manifestou timidamente seu desconforto com as políticas adotadas pelo governo federal, que lhe retiraram a exclusividade sobre as rotas internacionais e estimularam a competição via aumento da oferta num contexto de crise mundial. $\mathrm{Na}$ "Mensagem da Diretoria" do relatório de 1991, afirmava-se que

não obstante os indiscutíveis benefícios que o regime competitivo proporciona ao público usuário, a disputa acirrada de fatias de demanda em retração acabou por comprometer os resultados da indústria a nível mundial. (...) A Varig está atenta e acompanhando as mudanças, mesmo não concordando com algumas das políticas adotadas ( $\ldots$ e e) reconhece a tendência mundial de sobrevivência, apenas, das empresas mais competitivas e se prepara em todas as frentes para assegurar sua presença nesse universo (Relatório Anual 1991, p. 3).

Mesmo não sendo mais a "empresa de bandeira" do país, a Varig manteve-se como a transportadora oficial de Fernando Collor em seus deslocamentos internacionais e manteve vivo o imaginário de "grande empresa" legado das administrações anteriores. Uma mensagem dirigida aos aeronautas da empresa pela sua gerência revela a manutenção do imaginário da "Varig Grande":

A Varig, enquanto grande empresa brasileira e líder latino-americana, é ímpar no contexto mundial; definitiva e constantemente tem que entrar com o seu necessário gigantismo, que lhe exige crescimento constante para que seja garantida sua sobrevivência (Mensagem da Gerência de Comissariado de Vôo apud Speech 1990, n. 66, grifos meus). ${ }^{19}$

Já no início de 1992, contudo, o então presidente da empresa Rubel Thomas reconhecia que a estrutura da Varig havia crescido muito, para uma expectativa de aumento da demanda que não se concretizara. Pela primeira vez, a empresa teria que promover um expressivo corte de funcionários (Rosa

19 Neste sentido, a Varig inaugurou, em 1992, uma longa rota para a Ásia, ligando o Brasil à Tailândia e Hong Kong através da África do Sul, não sem pesados investimentos em publicidade e infra-estrutura, inclusive o aluguel de um Boeing 747-400, maior dentre os mais modernos jatos no mercado (Rosa dos Ventos, n. 114, 1992, p. 2). 
dos Ventos, n. 109, 1992, p. 2). O discurso predominante começaria, a partir de então, a se afastar da imagem de "Varig Grande" e começar uma transição para uma visão de "empresa enxuta", ${ }^{20}$ mudança que teria como corolário a substituição da imagem de empresa a serviço do desenvolvimento nacional por uma imagem de empresa a serviço do retorno financeiro. O Relatório Anual de 1992 revela a co-existência destes elementos, colocando logo após "os clientes", "o lucro para os acionistas". A contribuição para o país ficaria em último lugar, devidamente qualificada com um "sem ufanismo":

São nossas metas e compromissos permanentes o melhor serviço para os clientes, o lucro para os acionistas, o incentivo ao desenvolvimento pessoal e profissional de nossos colaboradores, a interação com a comunidade, visando ao bem comum e à preservação ambiental e, sem ufanismo, ser fator de peso para a integração e o progresso do Brasil, cuja bandeira desejamos dignificar e tornar cada vez mais presente nos mercados internacionais (Relatório Anual da Diretoria, 1992, p. 3, grifos meus).

À medida que avançam os anos noventa, a visão de "empresa enxuta" ganha mais espaço, invertendo a perspectiva que predominou na fase anterior. Se nos anos setenta eram valorizados a incorporação de novas rotas, novas aeronaves e o crescimento do corpo funcional, o Relatório da Diretoria de 1994 informava que alguns dos "progressos diretamente mensuráveis" alcançados após uma de suas sucessivas crises ao longo da década (primeiro semestre de 1994) foram a redução de 3.586 postos de trabalho, redução do número de diretores, redução na frota, o cancelamento e a alteração de rotas e, por fim, a terceirização do serviço de refeições de bordo, que fora um dos ícones da "Varig Grande", identidade da qual a empresa procurava se afastar (Relatório Anual da Diretoria, 1994, p. 3).

Consolidando esta nova visão, uma "Mensagem da Presidência" publicada no relatório de 1995, já então ocupada por Fernando Pinto, afirma que foram vencidas algumas etapas no sentido de recuperar a Varig, tais como a abertura do Conselho de Administração a profissionais de fora da empresa (e

20 Muitos autores falaram do modelo lean and mean, que caracterizaria a cultura empresarial da década de 1990. Dentre estes, Fligstein (1997a; 1997b) enfatiza a emergência de uma concepção de empresa exclusivamente voltada para o retorno aos acionistas, desconsiderando que para seu funcionamento, as empresas dependem de uma série de recursos que são garantidos por toda a sociedade, tais como infra-estrutura, qualificação profissional e instituições políticas estáveis que assegurem a confiança do capital. 
portanto, menos comprometidos com qualquer reminiscência da cultura empresarial pretérita), nova redução no número de diretorias e, ainda, a redução de mais 7.089 postos de trabalho, além do fechamento de lojas e escritórios no Brasil e no exterior, cancelamento de rotas e redução na frota (Rosa dos Ventos, n. 157, 1997, p. 13, grifos meus).

A Varig, então, passou a investir numa nova imagem corporativa, com uma nova pintura em seus aviões, buscando "transmitir uma imagem de modernidade". Da construção desta nova imagem fez parte, também, o ingresso da Varig na Star Alliance, um acordo operacional entre empresas de diferentes países visando a redução de custos através da integração de operações assentos compartilhados nos vôos, acesso a salas vip, utilização dos prêmios oferecidos pelos programas de milhagem, entre outros. A participação nesta aliança foi assim interpretada por Fernando Pinto: "A Star Alliance é uma grande idéia para todos nós. É a grande visão de futuro, a grande possibilidade de crescimento e desenvolvimento da Varig" (Rosa dos Ventos, n. 157, 1997, p. 13, grifos meus).

A Varig passou, então, a se representar como uma empresa global, integrada ao mercado mundial através de parcerias, ao mesmo tempo em que priorizava os resultados financeiros e não mais se representava como "empresa a serviço do país". Vale, ainda, citar o então Diretor Comercial da empresa, que numa entrevista sintetiza a identidade da Nova Varig.

Vamos ser uma empresa global, que cada vez mais pensa o mercado mundial, que vai ter o inglês como a segunda língua fluente, vai ser líder na América do Sul, vai ser rentável e terá uma marca cada vez mais forte. Teremos um corpo funcional profissionalizado, com uma produtividade semelhante à verificada mundialmente e com uma cultura voltada ao resultado (Rosa dos Ventos, n. 157, 1997, p. 4, grifos meus).

Emblemática desta nova relação de significado com a sociedade brasileira foi a resposta deste mesmo diretor à pergunta "Que contribuição a nossa empresa poderá oferecer para o incremento do turismo no Nordeste?":

Eu inverteria esta pergunta. Qual a contribuição que o Nordeste poderá oferecer para o incremento das vendas da Varig? A Varig tem feito esforços no sentido de criar novas ofertas. Ainda que a malha possa ser eventualmente melhorada, sempre existe a preocupação de medir a contribuição que esse tráfego vai dar para a nossa empresa (Rosa dos Ventos, n. 157, 1997, p. 5). 
Nesta fase, parece estar consolidado o discurso em torno da imperiosidade de uma cultura empresarial voltada para a competividade global, o que parecia adequado ao modelo de política econômica vigente. Com efeito, dentro do espírito das reformas para o mercado, a via para o crescimento estaria na capacidade de competir dentro de um mercado que ultrapassava os limites nacionais, e caberia aos agentes econômicos - com destaque para as empresas - buscar os meios necessários para garantir seu espaço dentro deste jogo.

No caso da Varig, o desempenho ao longo dos anos 1990 foi bastante instável. Acompanhando grosso modo os ciclos de stop-and-go da economia brasileira, a Varig viveu momentos de crise e fases de recuperação. Entre 1997 e 1998, por exemplo, a Varig chegou a anunciar investimentos no valor de US\$ 2,7 bilhões na compra de 39 jatos da norte-americana Boeing, ${ }^{21}$ após as sucessivas ondas de cortes citadas anteriormente. Este breve interregno de crescimento encerrou-se, no entanto, junto com a primeira grande crise da aviação comercial desde o Plano Real, com a desvalorização da moeda brasileira frente ao dólar em janeiro de 1999. A diminuição drástica na procura por viagens internacionais e o imediato aumento nos custos para as empresas brasileiras, sem a possibilidade de repassá-lo às tarifas devido à rígida política de controle por parte das autoridades econômicas, levaram a um retraimento expressivo do mercado. ${ }^{22}$

Deve-se mencionar, ainda, as estratégias relativas ao usuário, onde a Varig investiu em políticas de ampliação do acesso ao serviço, com a instituição em 1990 de tarifas promocionais com 25\% de desconto e crediário (Rosa dos Ventos, n. 100, 1990, p. 11) e do "Consórcio de Viagens Varig", em 1993 (Rosa dos Ventos, n. 116, 1993, p. 3). Ao longo destes anos, as faixas de desconto foram aumentando progressivamente, até que Fernando Pinto lançou, em fins de 1997, o programa Voa Brasil, com vôos diários entre algumas capitais brasileiras, durante a madrugada, oferecendo uma média de $50 \%$ de desconto em todos os assentos. Na mesma época, acompanhando uma onda de liberalização do mercado promovida pelo DAC por pressão das autorida-

21 Jornal do Brasil, 22 mar. 1998, e Gazeta Mercantil, 20 jul. 1998.

22 Uma análise mais detalhada das idas e vindas do mercado de aviação comercial ao longo dos anos 1990 e início da década seguinte se encontra em Monteiro (2004). 
des econômicas, e acompanhando as ofertas da Vasp e Tam, a Varig passou a oferecer descontos de até $60 \%$ em todas as suas rotas. ${ }^{23}$

Não obstante, todas as estratégias comerciais voltadas para a ampliação do acesso ao serviço de transporte aéreo tiveram curta duração na empresa: o crediário, o consórcio de viagens, o "Voa Brasil" e as tarifas com descontos de até $60 \%$. Por outro lado, estratégias voltadas para o público de mais alto poder aquisitivo, tais como as "Salas Vip", o programa de fidelidade e a introdução da classe Executiva nos vôos domésticos foram mantidos, visando enfrentar principalmente a concorrência da Tam, empresa que vinha crescendo no mercado doméstico graças a uma estratégia de serviço de bordo sofisticado, com foco no público de homens de negócio e afins. ${ }^{24}$ Este padrão, que marcou as estratégias da Varig ao longo dos anos 1970 e se mostrou persistente até a virada para o novo milênio, só viria a ser definitivamente desafiado com a entrada em cena de um novo ator no cenário da aviação comercial brasileira: a Gol Linhas Aéreas. ${ }^{25}$

Embora este novo contexto não seja o foco da presente análise, cumpre assinalar que se tratou de uma fase em que as transportadoras mais antigas do setor acabariam sucumbindo às dificuldades. A Transbrasil e a Vasp pararam de voar, respectivamente em 2001 e 2005, enquanto a Varig se viu próxima do mesmo fim em 2006. Beneficiada pela Nova Lei de Falências, a ex-líder

23 Como demonstrado em outro trabalho (Monteiro, 2004), a "onda liberalizante" do período foi fruto da pressão das autoridades econômicas e do núcleo do Executivo sobre as autoridades aeronáuticas, sob a ameaça da abertura do mercado doméstico às empresas estrangeiras e da exclusão dos militares do controle do setor, com a criação de um novo órgão (civil) para controlar a atividade, em substituição ao DAC. De opositores à liberalização, os militares da Aeronáutica passaram a reivindicar a liderança do processo.

24 A Tam veio a ser considerada uma empresa que revolucionou o atendimento ao cliente no Brasil, ganhando prestígio junto aos homens de negócio e ocupando importante fatia do mercado, com destaque para as rotas a partir do aeroporto de Congonhas-SP, o mais movimentado do país. As estratégias da Tam são analisadas, de um ponto de vista gerencial, por Lobos (1996).

25 A principal estratégia da nova empresa foi adotar o modelo low cost, low fare, com simplificação do serviço de bordo, padronização da frota e oferta de preços reduzidos, seguindo algumas experiências bem-sucedidas nos Estados Unidos e na Europa. Eventualmente, todas as empresas brasileiras adotaram um padrão semelhante (eliminando refeições quentes e outros itens do serviço de bordo, reduzindo a distância entre as poltronas e a Classe Executiva nos vôos domésticos), e passaram a investir na oferta de tarifas mais competitivas, de modo que nos últimos anos o conjunto do setor parece ter abandonado o foco exclusivo nos passageiros de maior poder aquisitivo que marcou as décadas anteriores. 
da aviação comercial brasileira foi preservada com a entrada de um novo investidor, que assumiu a parte "operacional" da empresa, envolvendo a própria marca, os espaços nos aeroportos e rotas da empresa. Do sucesso desta nova fase, dependerá a parte "velha" da Varig (que ficou com as dívidas com fornecedores e o poder público, o passivo trabalhista, um centro de treinamento e alguns imóveis) para dar conta dos compromissos nãohonrados. De qualquer forma, este é um novo contexto, cujo desenho ainda não se encontra de todo definido, merecendo uma análise própria que leve em conta as especificidades do novo ambiente econômico que se apresenta no início do século XXI.

\section{Considerações finais}

Este artigo pretendeu desenvolver uma abordagem sociológica sobre as estratégias empresariais, mostrando que estas estratégias podem ser entendidas de uma forma que ultrapassa a visão economicista convencional. Para além de ser um ator mobilizado para a sobrevivência no mercado e para o lucro, a empresa é um ator social no sentido de se articular às dinâmicas sociais nas quais está inserida. Procurei mostrar isso através da articulação das estratégias empresariais com as políticas governamentais vigentes em dois contextos distintos da história recente do Brasil: os anos 1960-70, em que predominou uma política de valorização do desenvolvimento nacional (o "Brasil grande"); e os anos 1990, em que ganhou ascendência uma política de inserção competitiva na dinâmica da economia global.

No primeiro período, foram decisivas para o crescimento e a consolidação da empresa, a articulação com os grupos ocupantes do poder público, desde Getúlio e seus herdeiros até os militares, e a incorporação de uma identidade de "empresa a serviço do país" e de "Varig Grande". No contexto das reformas neoliberais, a empresa procurou se identificar com um projeto de "competitividade global", como "empresa enxuta" exclusivamente voltada para o resultado financeiro. Desta forma, passaram a ser valorizados os cortes no número de funcionários, a diminuição das rotas e da frota, assim como a busca de um maior vínculo com a dinâmica da economia global, o que ficou evidente com a entrada da transportadora na Star Alliance. 
Mesmo não sendo o objetivo deste trabalho, cabem algumas considerações sobre a questão da crise da Varig, à luz de sua trajetória. Em primeiro lugar, deve-se salientar o descompasso entre as estratégias adotadas ainda no início dos anos 1990 e o ambiente político-econômico vigente no país. Apesar de ter patrocinado uma primeira onda de liberalização do setor aéreo, com a extinção da exclusividade da Varig na designação das rotas internacionais, a Varig continuou servindo de transportadora oficial de Fernando Collor em seus deslocamentos, dentro do espírito de "empresa a serviço do país" que marcara as fases anteriores. Por outro lado, continuou lançando-se a projetos ambiciosos, como a rota para Hong Kong, pautada em uma visão de "Varig Grande", apesar do ambiente de crise e grande incerteza na economia.

Superado este descompasso, a empresa passou a investir na imagem de uma empresa comprometida com a "competitividade global". O que a trajetória subseqüente da companhia aérea mostra é que, a despeito das mudanças, a estratégia não foi bem-sucedida. A lógica do lean and mean não necessariamente cumpriu a promessa de maior competitividade e de sobrevivência no mercado. Os analistas e comentaristas econômicos que acompanharam a progressiva deterioração da situação financeira da Varig insistiram que a empresa continuou "pesada", com custos elevados em relação às congêneres. Falou-se muito, também, de uma suposta capacidade de interferência que os funcionários teriam na gestão da empresa, por conta do modelo de fundação. Mas o fato é que a empresa eliminou milhares de postos de trabalho, reduziu suas operações para concentrar-se nos nichos mais rentáveis e buscou uma inserção na dinâmica da globalização, tal como se apresentava no período.

Não obstante, algumas das tendências identificadas no início deste artigo a respeito da crescente importância da dimensão "social" do universo das empresas, sugerem a insuficiência de um foco exclusivo no problema dos resultados financeiros. Parece uma verdade cristalina que as empresas não podem sobreviver sem o lucro. Menos óbvio, mas não menos importante, é entender que a construção da empresa como um ator social (na qual a questão do lucro é uma das dimensões a serem consideradas) consiste num problema bem mais complexo e, ao mesmo tempo, desafiador. Neste sentido, a Sociologia da Empresa pretende trazer para o foco da análise um conjunto mais amplo de variáveis que a visão economicista não reconhece como relevantes. 
A trajetória da Varig, neste sentido, parece ser um caso "bom para pensar" sobre a validade e a pertinência de uma leitura sociológica da empresa como um dos caminhos pelos quais a Sociologia do Século XXI pode contribuir na busca da retomada do desenvolvimento e do crescimento econômico em novas bases. Não se trata, vale lembrar, de opor a uma lógica econômica (do resultado financeiro e da competitividade) uma lógica "social" (do altruísmo, da busca do bem comum), como muitas vezes a Sociologia acaba sendo representada no senso comum. Trata-se de uma proposição mais ousada, que visa reconhecer na Sociologia um saber capaz de discutir os problemas estratégicos ligados a um ator fundamental para a questão do desenvolvimento econômico.

\section{Referências}

ANDERSON, Dole. Aviação comercial brasileira. João Pessoa, PB: Ed. Ufpb. 1979.

BERNOUX, Philippe. La sociologie des entreprises. Paris: Seuil, 1995.

BRANDÃO, Nadja A fundação da Varig no periodo republicano e positivista do chimango Borges de Medeiros. Porto Alegre: Ifch/PUCRS, Mimeo, 1994.

BOYER, Robert. L'après-consensus de Washington: institutionnaliste et systémique? L'Année de la Régulation, Paris, n. 5, p. 13-56, 2001.

CASTRO, Newton de; LAMY, Phillipe. Desregulamentação do setor transporte: o subsetor transporte aéreo de passageiros. Brasília e Rio de Janeiro: Ipea, Texto para discussão n. 319, 1993.

DINIZ, Eli. Globalização, reformas econômicas e elites empresariais. Rio de Janeiro: FGV, 2000.

DRACHE, Daniel. From Keynes to K-Mart. Competitiveness in a corporate age. In: BOYER, R. e - (Orgs.). States against markets. The limits of globalization. Londres e Nova Iorque: Routledge, 1996, p. 31-61.

FAY, Claudia. Crise nas alturas: a questão da aviação civil. Tese de Doutorado em História. Porto Alegre: Ppgh/Ifch/Ufrgs, 2001.

FLIGSTEIN, Neil. Rhétoriques et réalités de la 'mondialisation'. Actes de la recherche en sciences sociales, Paris, n. 119, p. 36-47, 1997a.

- Markets, politics, and globalization. Uppsala: Acta Universitatis Upsaliensis, 1997b.

Press, 1990. 
FRANCFORT, Isabelle; OSTY, Florence; SAINSAULIEU, Renaud; UHALDE, Marc. Les mondes sociaux de l'entreprise. Paris: Desclée de Brower, 1995.

GONÇALVES, Jussara Maria Siqueira. Ruben Berta: a experiência de socialização através de uma fundação de funcionários. Dissertação de Mestrado em Sociologia. Porto Alegre: Ifch/PUCRS, 1987.

IANNI, Octávio. Teorias da globalização. Rio de Janeiro: Civilização Brasileira, 1996.

KIRSCHNER, Ana Maria; GOMES, Eduardo (Org.). Empresa, empresários e sociedade. Rio de Janeiro: Sette Letras, 1999.

— ; CAPPELLIN, Paola (Orgs.). Empresa, empresários e globalização. Rio de Janeiro: Relume Dumará, 2002.

; MONTEIRO, Cristiano. Da sociologia econômica à sociologia da empresa: para uma sociologia da empresa brasileira. Sociedade e Estado, Brasília, v. 17, n. 1, p. 79-103, mar.-jun. 2002.

LIU, Michel. L'autonomie des entreprises dans le champ social. In: SAINSAULIEU, Renaud (Org.). L'entreprise: une affaire de société. Paris: Fondation Nationale de Science Politique/Réference, 1992, p. 119-130.

LOBOS, Júlio. O céu não é o limite para a empresa brasileira que quer vencer. São Paulo: Instituto de Qualidade, 1996.

LOPES JR., Edmílson. As potencialidades analíticas da nova sociologia econômica. Sociedade e Estado, Brasília, v. 17, n. 1, p. 39-62, mar.-jun. 2002.

MONTEIRO, Cristiano. Aviação comercial, globalização e a experiência brasileira. Revista Brasileira de Direito Aeroespacial, Rio de Janeiro, n. 79, p. 17-25, mar. 2000.

. A dinâmica política das reformas para o mercado na aviação comercial brasileira (1990-2002). Tese de Doutorado em Sociologia, Rio de Janeiro: Ppg$\mathrm{sa} / \mathrm{Ifcs} / \mathrm{Ufrj}, 2004$.

POLANYI, Karl. The great transformation. The political and economic origins of our time. 3. ed. Boston: Beacon Press, 1944.

RAMANATSOA, Bernard. L'autonomie stratégique de l'entreprise. In: SAINSAULIEU, Renaud. (Org.). L'entreprise: une affaire de société. Paris: Fondation Nationale de Science Politique/Réference, 1992, p. 131-147.

SAINSAULIEU, Renaud. Sociologie de l'entreprise. Organisation, culture et développement. $2^{\mathrm{a}}$ ed. Paris: Presse de Science Po/Dalloz, 1997.

—. Introduction. Changer l'entreprise, une affaire de société. In: — (Org.). L'entreprise: une affaire de société. Paris: Fondation Nationale de Science Politique/Réference, 1992, p. 13-27. 
SWEDBERG, Richard; GRANOVETTER, Mark. Introduction. In: (orgs.). The sociology of economic life. Boulder, San Francisco e Oxford: Westview Press, 1992, p. 1-26.

WANDERLEY, Fernanda. Avanços e desafios da nova sociologia econômica. Notas sobre os estudos sociológicos do mercado. Sociedade e Estado, Brasília, v. 17, n. 1, p. 15-38, mar.-jun. 2002.

XAUSA, Maria Regina. A importância das instituições e o desafio à liderança institucional. O caso Varig, Dissertação de Mestrado, Porto Alegre: Faculdade de Ciências Econômicas/Ufrgs, 1993.

\section{Fontes sobre aviação comercial e a Varig}

III PDSAC. III Plano de Desenvolvimento do Sistema de Aviação Civil. Brasília: Ministério da Aeronáutica/Departamento de Aviação Civil, 1988.

BARBOSA, Nair Palhano. Nas asas da história: lembranças da Panair do Brasil. Rio de Janeiro: Agir, 1996.

DAVIES, Ron. Airlines of Latin America since 1919. Washington D.C.: Smithsonian Institution Press, 1984.

FUNDAÇÃO RUBEN BERTA. De homens e ideais: os cinqüenta anos da Fundação Ruben Berta. São Paulo: Prêmio, 1996.

MOURA, Nero. Um vôo na história. Rio de Janeiro: FGV, 1996.

PEREIRA, Aldo. Breve história da aviação comercial brasileira. Rio de Janeiro: Europa. 1987.

RELATÓRIOS ANUAIS DA DIRETORIA DA VARIG, 1968-1995.

ROSA DOS VENTOS, 1960-1998.

RIBEIRO, Luciano. Traçando o caminho dos céus. O departamento de aviação civil: 1931-2001. Rio de Janeiro: Action, 2002.

TORRES, Vasconcelos. Aviação, presença antiga na integração nacional. Brasília: Serviço Gráfico do Senado Federal, 1971. 